\title{
Heterotopic Ossification Causing Radiculopathy after Lumbar Total Disc Arthroplasty
}

\author{
Keith L. Jackson, Justin M. Hire, Jeremy M. Jacobs, Charles C. Key, John G. DeVine \\ Department of Orthopaedics and Rehabilitation, Dwight D. Eisenhower Army Medical Center, Fort Gordon, GA, USA
}

To date, no reports have presented radiculopathy secondary to heterotopic ossification following lumbar total disc arthroplasty. The authors present a previously unpublished complication of lumbar total disk arthroplasty (TDA) secondary to heterotopic ossification $(\mathrm{HO})$ in the spinal canal, and they propose a modification to the McAfee classification of HO. The patient had undergone an L5/S1 lumbar TDA two years prior due to discogenic back pain. His preoperative back pain was significantly relieved, but he developed new, atraumatic onset radiculopathy. Radiographs and a computed tomography myelogram revealed an implant malposition posteriorly with heterotopic bone formation in the canal, causing an impingement of the traversing nerve root. Revision surgery was performed with implant extraction, L5/S1 anterior lumbar interbody fusion, supplemental posterior decompression, and pedicle screw fixation. The patient tolerated the procedure well, with complete resolution of the radicular leg pain. At a two-year follow up, the patient had a solid fusion without subsidence or recurrence of heterotopic bone. This case represents a novel pattern of heterotopic ossification, and it describes a previously unreported cause for implant failure in lumbar disc replacement surgery-reinforcing the importance of proper intraoperative component positioning. We propose a modification to the existing McAfee classification of HO after TDA with the addition of Class V and VI HO.

Keywords: Heterotopic ossification; Total disc arthroplasty; Radiculopathy

\section{Introduction}

As of 2005, lumbar disc disorders and their associated lower back pain have an annual cost of in excess of $\$ 100$ billion dollars [1]. Treatments for these disorders include nonoperative management strategies, arthrodesis, and, more recently, total disc arthroplasty. Traditionally, arthrodesis has been the first line of surgical treatment for lumbar disc disorders. However, such procedures alter lumbar motion kinematics and risk accelerating the degeneration of adjacent motion segments. A total disc arthroplasty is a relatively new treatment strategy for lumbar discogenic back pain that has shown promis- ing short- and intermediate-term results [2-4]. Specific complications that can accompany total disc arthroplasty include vertebral body fracture, heterotopic ossification (HO), implant malposition, and early or late component extrusion [2,4-6]. In this report, we present a case in which posterior component placement contributed to heterotopic bone growth within the spinal canal, causing neural impingement and radiculopathy and ultimately requiring component extraction, decompression, and lumbar arthrodesis. The purpose of this report is to describe a previously unidentified complication and to emphasize the importance of appropriate component positioning. In addition, we suggest a modification to the current classifi-

Received Jun 5, 2014; Revised Jul 18, 2014; Accepted Jul 18, 2014

Corresponding author: Justin M. Hire

Department of Orthopaedics and Rehabilitation, Dwight D. Eisenhower Army Medical Center,

300 Hospital Road, Fort Gordon, GA 30905, USA

Tel: +1-706-787-1859, Fax: +1-706-787-2901, E-mail: justin.m.hire.mil@mail.mil 
cation for $\mathrm{HO}$ associated with total disc arthroplasty.

\section{Case Report}

A 45-year-old male was admitted to our clinic due to new onset right leg pain. The patient had undergone an L5S1 lumbar total disk replacement two years prior with an SB Charite disk (Depuy Spine, Raynham, MA, USA) as a result of discogenic back pain. Following surgery, he reported a significant relief of his initial symptoms but developed new, atraumatic onset right leg pain over the six months prior to visiting our clinic. The radicular pain had failed to significantly improve with a course of nonoperative treatments consisting of physical therapy, nonsteroidal anti-inflammatory medications, and epidural steroid injections. He denied paresthesias or the loss of motor function, and he also denied a prior history of $\mathrm{HO}$ forma- tion, trauma, or inflammatory arthritis.

A physical examination revealed a well-healed abdominal surgical scar, and the lumbar range of motion was limited in forward flexion secondary to right leg pain, with near full motion in all other planes. A straight leg raise reproduced the patient's symptoms, and a neurologic examination revealed 5/5 motor strength in all major muscle groups with intact sensation to light touch in all lower extremity dermatomes. The patellar and achilles reflexes were $2+$ and symmetric. On presentation, radiographs demonstrated implant encroachment into the spinal canal with heterotopic bone formation outside the margins of the disc (Fig. 1). A computed tomography myelogram (Fig. 2) revealed compression of the traversing nerve root secondary to the inferior endplate of the implant that resided posterior to the margin of the vertebral endplate as well as an associated posterior bone growth further into the
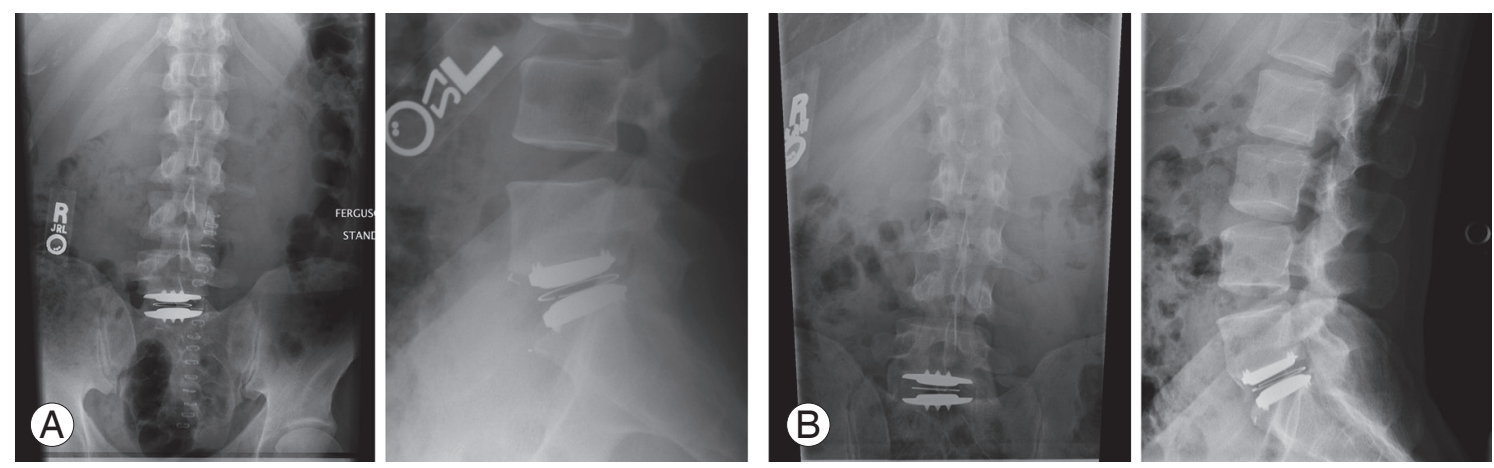

Fig. 1. (A) Postoperative radiographs from the index procedure demonstrating initial posterior placement of the implant. (B) Radiographs at presentation demonstrating implant encroachment into the spinal canal with heterotopic bone formation outside of the margins of the disc.
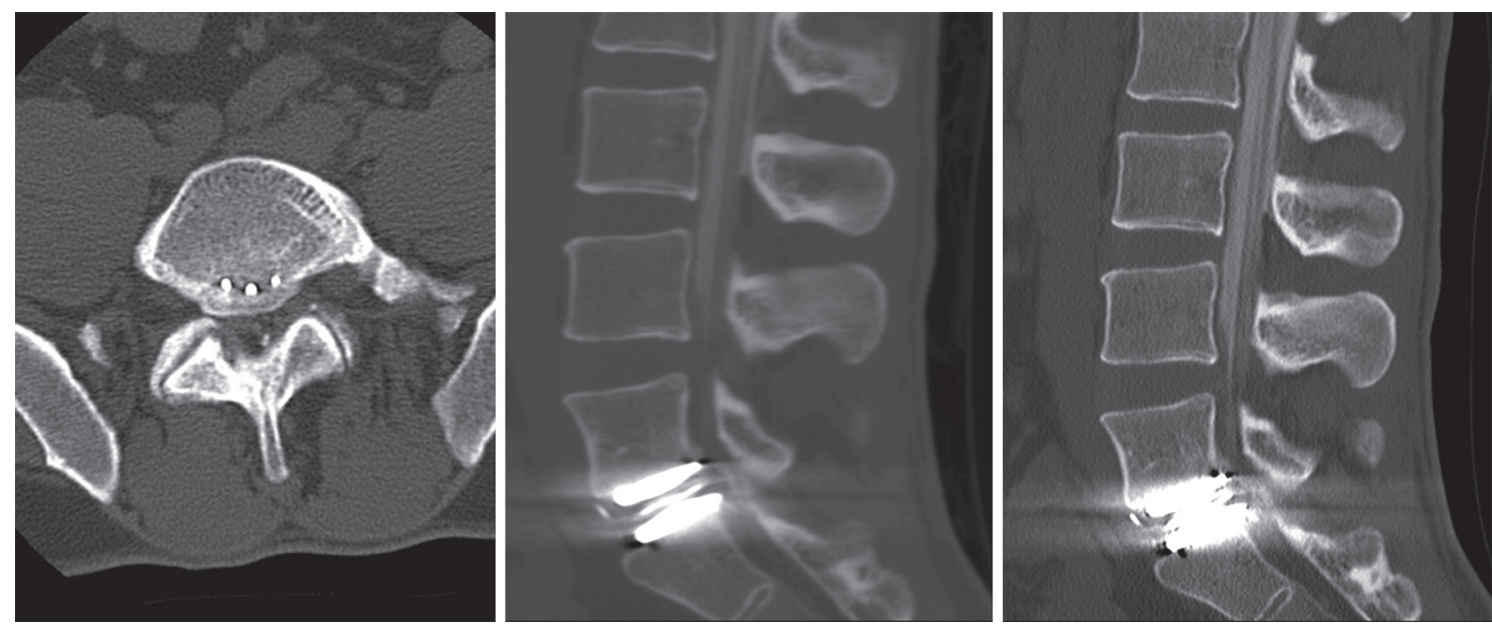

Fig. 2. Computed tomography myelogram with indications of compression of the traversing nerve root secondary to the inferior endplate of the implant residing posterior to the margin of the vertebral endplate as well as associated posterior bone growth into the canal. 
canal.

Since the symptoms failed to improve with non-operative management, the patient elected to undergo a revision surgery to extract the implant and to perform an L5/ S1 anterior lumbar interbody fusion. Ureteral stents were placed to facilitate mobilization and identification of the ureters intraoperatively. The implant was then removed, and a polyetheretherketone interbody spacer filled with an autologous iliac crest bone graft was placed anteriorly. This was followed by a posterior hemilaminotomy and decompression of the traversing S1 nerve root with removal of heterotopic bone originating from the superior endplate of S1. The heterotopic bone of this location and small islands of $\mathrm{HO}$ were decompressed with kerrison rongeur and curettes. The pedicle screw instrumentation was placed to supplement the interbody fusion. The patient tolerated the procedure well, with a blood loss of 400 $\mathrm{mL}$, and was discharged to return home on postoperative day 3. During his 6-week postoperative visit, the patient reported complete relief of his radicular leg pain, and during his most recent 2-year follow-up, the patient continued to note improvements in both leg pain and quality of life. The radiographs at that time demonstrated a solid fusion without subsidence or recurrence of heterotopic bone formation (Fig. 3).

\section{Discussion}

$\mathrm{HO}$ is a commonly recognized phenomenon following lumbar disc arthroplasty with reported rates varying between $1.4 \%$ to $83 \%$ [5,7-11]. In an attempt to standardize the description of this pathology, McAfee developed the first and still most commonly used classification scheme specifically for total disc arthroplasty [12,13]. This reliable and reproducible system divides $\mathrm{HO}$ into five categories: Class 0, no HO; Class I, island of bone not within the margins of the disc and not interfering with motion; Class II, bone within the margins of the disc but not interfering with motion of the prosthesis; Class III, bone within the margins of the disc interfering with range of motion; and Class IV, bony ankylosis $[13,14]$.

The case report is unique in that it presents a pattern of $\mathrm{HO}$ within the spinal canal that has not been previously described in the McAfee classification. While McAfee's system primarily addresses the location of the $\mathrm{HO}$ and the effects on motion, our patient's ossification pattern caused an impingement on the traversing neural elements that required reoperation and, specifically, decompression of the traversing nerve root. An extensive search of the existing literature in the English language found no reports of similar cases. Though the absence of other reports likely
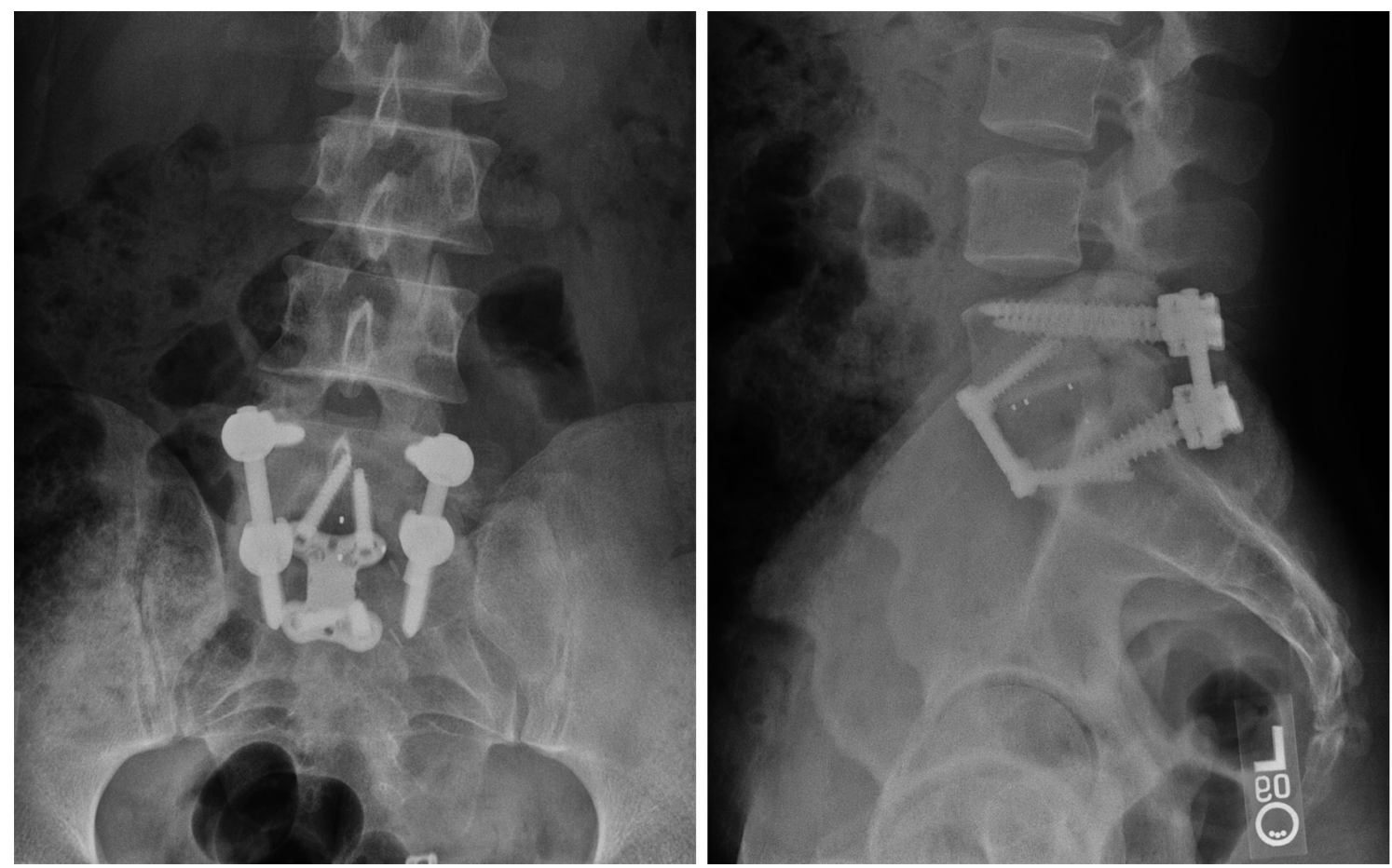

Fig. 3. Two-year follow-up films demonstrating solid fusion in an appropriate alignment with no heterotopic ossification. 
Table 1. Modified McAfee classification for heterotopic bone after total disc arthroplasty

\begin{tabular}{ll} 
Class & Description \\
I & No heterotopic ossification \\
III & Bone within the margins of the disc and not interfering with motion \\
IV & Bone within the margins of the disc interfering with range of motion \\
$V$ & Bone within the canal without symptomatic neural impingement \\
$V I$ & Bone within the canal with symptomatic neural impingement \\
\hline
\end{tabular}

indicates that symptomatic ossification within the canal following lumbar disc replacement is extremely rare, the unique pattern of failure warrants specific consideration. This is particularly true when evaluating patients with new, onset radiculopathy after total disc arthroplasty.

We hypothesize that the cause of this pathology was the initial posterior malposition of the component. Using the SB Charite' (Depuy Spine), McAfee correlated the implant position to clinical outcomes and to component range of motion [13]. In this study the "central" position was defined as a point $2 \mathrm{~mm}$ posterior to the middle of the vertebral body in the sagittal plane and the center of the vertebral body in the coronal plane [14]. The position of the implant within $3 \mathrm{~mm}$ of the central position in both the coronal and mid-sagittal planes was deemed to be "ideal." A component position 3-5 mm from the central position was found to be suboptimal while a position more than $5 \mathrm{~mm}$ away was defined to be "malpositioned." This description of a malposition was based on anteriorposterior imaging. In the presented case, the component was initially malpositioned in the sagittal plane, $5 \mathrm{~mm}$ from the central position. This likely resulted in the formation of bone posteriorly just caudal to the inferior endplate, extending into the canal, and gradually resulting in impingement of the traversing nerve root. The radicular pain was exacerbated by forward flexion secondary tension placed on the traversing nerve root, much like that seen with a herniated disc, causing a "tension sign."

Though more commonly associated with a decrease in the component motion, symptomatic $\mathrm{HO}$ following lumbar total disc arthroplasty can cause neurologic impingement when a formation occurs posteriorly, thereby becoming a space occupying lesion. This case presents a novel pattern of heterotopic bone formation with a previously unreported cause of implant failure in lumbar disc replacement surgery. It also reinforces the importance of intraoperative component positioning to physicians offering lumbar disc arthroplasty. As a result of this report, we recommend a modification of the McAfee classification of $\mathrm{HO}$ after total disc arthroplasty by introducing: Class $\mathrm{V}$, bone within the canal but without symptomatic neural impingement; and Class VI, bone within the canal with symptomatic neural impingement (Table 1).

\section{Conflict of Interest}

No potential conflict of interest relevant to this article was reported.

\section{References}

1. Katz JN. Lumbar disc disorders and low-back pain: socioeconomic factors and consequences. J Bone Joint Surg Am 2006;88 Suppl 2:21-4.

2. Bertagnoli R, Yue JJ, Shah RV, et al. The treatment of disabling single-level lumbar discogenic low back pain with total disc arthroplasty utilizing the Prodisc prosthesis: a prospective study with 2-year minimum follow-up. Spine (Phila Pa 1976) 2005;30:2230-6.

3. Tropiano P, Huang RC, Girardi FP, Cammisa FP Jr, Marnay T. Lumbar total disc replacement. Seven to eleven-year follow-up. J Bone Joint Surg Am 2005;87: 490-6.

4. Tropiano P, Huang RC, Girardi FP, Marnay T. Lumbar disc replacement: preliminary results with ProDisc II after a minimum follow-up period of 1 year. J Spinal Disord Tech 2003;16:362-8.

5. van Ooij A, Oner FC, Verbout AJ. Complications of artificial disc replacement: a report of 27 patients with the SB Charite disc. J Spinal Disord Tech 2003; 16:369-83.

6. Mehren C, Suchomel P, Grochulla F, et al. Heterotop- 
ic ossification in total cervical artificial disc replacement. Spine (Phila Pa 1976) 2006;31:2802-6.

7. Cinotti G, David T, Postacchini F. Results of disc prosthesis after a minimum follow-up period of 2 years. Spine (Phila Pa 1976) 1996;21:995-1000.

8. Griffith SL, Shelokov AP, Buttner-Janz K, LeMaire JP, Zeegers WS. A multicenter retrospective study of the clinical results of the LINK SB Charite intervertebral prosthesis: the initial European experience. Spine (Phila Pa 1976) 1994;19:1842-9.

9. Lemaire JP, Carrier H, Sariali el H, Skalli W, Lavaste F. Clinical and radiological outcomes with the Charite artificial disc: a 10-year minimum follow-up. J Spinal Disord Tech 2005;18:353-9.

10. Park SJ, Kang KJ, Shin SK, Chung SS, Lee CS. Heterotopic ossification following lumbar total disc replacement. Int Orthop 2011;35:1197-201.

11. Regan JJ. Clinical results of charite lumbar total disc replacement. Orthop Clin North Am 2005;36:323-40.

12. DeVine JG. Heterotopic ossification. In: Chapman JR, Dettori JR, Norvell DC, editors. Spine classification and severity measures. New York: Thieme; 2008. p.307-16.

13. McAfee PC, Cunningham BW, Devine J, Williams E, Yu-Yahiro J. Classification of heterotopic ossification (HO) in artificial disk replacement. J Spinal Disord Tech 2003;16:384-9.

14. McAfee PC, Cunningham B, Holsapple G, et al. A prospective, randomized, multicenter Food and Drug Administration investigational device exemption study of lumbar total disc replacement with the CHARITE artificial disc versus lumbar fusion: part II: evaluation of radiographic outcomes and correlation of surgical technique accuracy with clinical outcomes. Spine (Phila Pa 1976) 2005;30:1576-83. 